\title{
Os epigramas de Marcial e seus ritmos em português
}

\author{
Fábio Paifer Cairolli
}

\begin{abstract}
Resumo: $O$ artigo propõe um modelo de tradução poética dos epigramas de Marcial, contemplando a especificidade ritmica da obra latina com metros portugueses, quer recolbidos na tradição vernácula, quer criados especificamente para expressar características do original que se desejava manter no idioma de chegada. Seguir-se-á à exposição destes critérios uma coletânea com poemas traduzidos em cada um dos metros propostos.
\end{abstract}

Palavras-chave: Marcial; epigrama; tradução poética; teoria da tradução; métrica portuguesa.

Marco Valério Marcial (c. 40 - c. 105 d.C.) é o principal expoente de um dos gêneros poéticos mais praticados no período em que viveu, o epigrama, único gênero a que se dedicou. Chegaram-nos 15 livros em notável estado de conservação (apenas o Livro dos espetáculos, livro de estreia, apresenta indícios de preservação incompleta), nos quais se conservam cerca de 1500 poemas. Nesse conjunto, os dois aspectos mais importantes, ao nosso ver, são a matéria adequada ao gênero e os metros em que os epigramas são compostos.

As diversas matérias tratadas pelos epigramas acarretam a existência de espécies epigramáticas, que são explicitadas com certa precisão, como no caso dos antologistas da Antologia palatina, do autor do papiro de Milão ${ }^{1}$ e do epistológrafo e também poeta Plínio, o Jovem, amigo de Marcial. Embora haja algumas diferenças entre as classificações de Plínio e da Antologia palatina, não deixam de ser notáveis as semelhanças. Veja-se como Plínio fala de seus epigramas, hoje perdidos, na epístola 14 do livro IV:

1 O Papiro de Milão (P. Mil. Vogl. VIII, 309) é uma coleção de epigramas organizada por tema. Descoberta no início dos anos 1990, foi atribuída, com base nos dois epigramas conhecidos, a Posidipo de Pela, poeta grego helenístico do século III a.C. 
His iocamur, ludimus, amamus, dolemus, querimur, irascimur, describimus aliquid modo pressius modo elatius, atque ipsa uarietate temptamus efficere, ut alia aliis quaedam fortasse omnibus placeant.
Com os poemas, gracejei, brinquei, amei, sofri, reclamei, me irritei, descrevi algo ora mais conciso, ora mais distendido e por meio da própria variedade tentamos prosseguir, para que por meio de uns e outros pudesse talvez agradar a todos ${ }^{2}$.

Em outras palavras, para Plínio o epigrama, resumidamente, se prestaria a diversas matérias e, quando é o caso, a seus respectivos afetos: matéria jocosa (iocamur, ludimus, "gracejei, brinquei”, relacionável à matéria do volume XI da Antologia

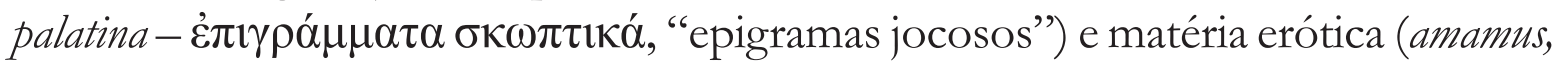

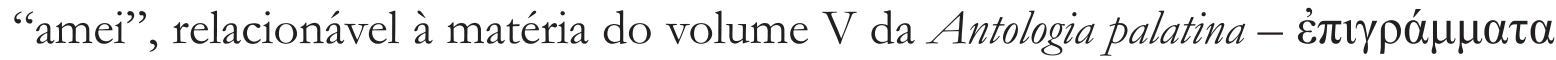

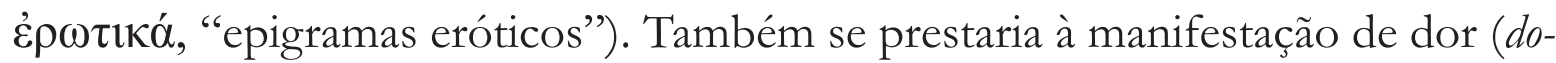
lemus, "sofri", relacionável primacialmente à morte e ao luto, e por isso ao volume

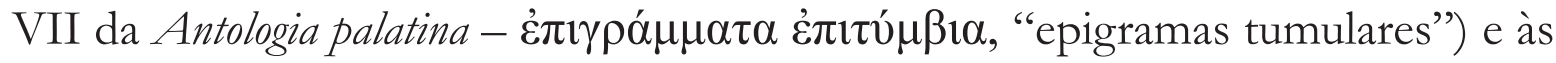
descrições (describimus, "descrevi", relacionável à matéria dos volumes II, III e

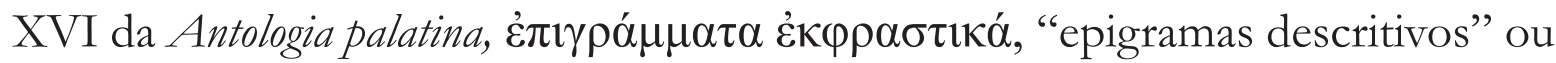
"ecfrásticos"). A única matéria e a respectiva espécie que parecem ausentes da larga explicitação da Antologia palatina - indignação e raiva (irascimur, "me irritei" e até "odiei") - são na verdade relacionáveis ao próprio gênero do epigrama, tal como o entendem os latinos.

Quanto aos metros, nos doze livros “de epigramas”, Marcial compõe poemas preferencialmente em três esquemas, a saber:

$\begin{array}{lll}\text { dístico elegíaco: } & 857 \text { poemas } & 73,2 \% \text { do total; } \\ \text { hendecassílabo falécio: } & 228 \text { poemas } & 19,5 \% \text { do total; } \\ \text { coliambo: } & 74 \text { poemas } & 6,32 \% \text { do total. }\end{array}$

Apenas 12 poemas são compostos em outros metros, a saber, dístico epódico (cinco poemas), hexâmetro datílico (quatro poemas), trímetro jâmbico (dois poemas) e tetrâmetro jônico (um poema). Quando se consideram os outros três livros de epigramas de Marcial, conhecidos como Xênia, Apoforetos e Livro dos espetáculos, escritos quase integralmente em dísticos elegíacos, aumenta a prevalência deste metro, que também é predominante na Antologia palatina. Os metros impor-

2 As traduções aqui apresentadas, salvo indicação contrária, são nossas. 
tam não somente pela relevância da circulação oral da poesia latina, a concretizar "espetacularmente", ao vivo, os ritmos, mas em particular também porque os epigramas, quando publicados em livro, como ocorreu com Marcial, apresentam no universo que é o volume outros dados que não se manifestam na leitura isolada de poucos epigramas. Entre esses dados está variedade métrica, a relação entre matéria e metro e a inter-relação de poemas no mesmo metro no interior de cada volume. Em nossa tese de doutorado, propusemo-nos a traduzir em verso todos os epigramas de Marcial em português e, como o fizemos integralmente, decidimos traduzir a variedade métrica de Marcial biunivocamente, isto é, para cada metro original utilizamos um metro diferente em português.

Com efeito, não há publicada nenhuma tradução poética integral dos epigramas de Marcial em nossa língua, e, seja como for, a maioria dos tradutores em verso de poemas isolados e de seleção temática ou não levou em conta os diferentes metros dos poemas originais - muito provavelmente por causa da própria proposta de traduzir uma seleção ${ }^{3}$ - ou, quando levou, não o fez biunivocamente . $^{4}$ Pareceu-nos oportuno que o contraste dos metros seja percebido em português, senão da mesma forma que nos poemas latinos, ao menos de modo análogo. Para tanto, investigamos as soluções apresentadas por tradutores lusófonos ao traduzir Marcial ou outros autores epigramáticos, como Catulo; quando não encontramos solução adequada ao projeto, criamos a nossa.

O dístico elegíaco, metro mais abundante na obra de Marcial, é a justaposição do hexâmetro datílico (isto é, composto por seis células datílicas) a um pentâmetro datílico, que é na verdade um hexâmetro datílico duplamente cataléctico. A bem dizer, dístico, muito antes dos epigramatistas, foi empregado pelos poetas elegíacos gregos, razão pela qual ficou assim conhecido. Para traduzi-lo, diversos ritmos foram adotados na poesia lusófona e o inventário de soluções está ainda por fazer. Acolhemos proposta de utilizar versos consolidados que logram exibir a mesma desigualdade do dístico antigo. Acreditamos que tal desigualdade não pode ser ignorada em uma tradução que se interesse pelos aspectos retórico-poéticos da poesia antiga. Assim, utilizamos um dístico composto por verso dodecassílabo com acento obrigatório na sexta sílaba, seguido de verso decassílabo heroico. Tal esquema métrico para verter o dístico latino está em circulação em nosso idioma pelo menos desde os anos 1960, quando foi empregado por Péricles Eugênio da

3 Por exemplo, José Paulo Paes, em Poesia erótica em tradução, traduz de Marcial somente epigramas eróticos.

4 Por exemplo Décio Pignatari, nos 57 epigramas de Marcial que integram os 31 poetas, 214, explora grande variedade rítmica e estilística, sem se ater aos metros latinos como referência. 
Silva Ramos em Poesia grega e latina para traduzir excerto da elegia II, 27 de Propércio (p. 199). A escolha deste tipo de dístico implica definirmos que os poemas em hexâmetros datílicos, verso ocasional nos epigramas, por coerência serão sempre traduzidos por dodecassílabos.

Para os epigramas compostos em hendecassílabos falécios, é eleição quase automática vertê-los por decassílabos, visto que tanto o metro latino como o português (quando não for esdrúxulo) possuem 11 sílabas ${ }^{5}$. Este modelo tem sido seguido por vários tradutores que transpõem poemas hendecassílabos de Marcial e de Catulo a partir do século XIX'.

Especial atenção mereceram os poemas compostos em escazonte, também chamado "coliambo". Este metro é composto por seis pés iâmbicos, dos quais o último claudica pois, em vez de mais um iambo, apresenta um troqueu ou espondeu. Veja-se exemplo:

Něgā / rĕ nūl / lăm quō / quěrōr / pǔēl / lārŭm (MART. IV, 81, 2).

No verso, até a última célula o andamento, por causa do iambo, é ascendente, isto é, há uma sílaba breve seguida de longa tônica dotada de icto, que é uma espécie de acento tônico. Na última célula, o troqueu impõe mudança de ritmo, que passa descendente, bem o oposto, isto é, sílaba longa e tônica seguida de breve e átona. Veja-se, por comparação, a regularidade, isto é, a ausência de variação rítmica, de um senário iâmbico perfeito, que é um verso de seis células iâmbicas:

Quǔs hōc / pŏtēst / uŭdē / rĕ, quīs / pŏtēst / pătī (CAT. 29, 1)

Próprio da poesia em que o elemento cômico está presente, o escazonte foi utilizado por poetas como o mimiógrafo Herodas de Siracusa, Calímaco de Cirene, Catulo e Marcial; contudo, não recebeu dos tradutores lusófonos tratamento que preservasse a claudicação.

A solução adotada por tradutores que verteram poeticamente poemas escritos em coliambos é geralmente o decassílabo ou o dodecassílabo, por vezes

5 Lembramos que até a publicação do tratado de métrica de Antônio Feliciano de Castilho era hábito em Portugal contar todas as sílabas do verso e não só até a última sílaba tônica, como ele fez por influência dos tratados francesses. Assim, o verso que, contado à francesa, costumamos chamar até hoje "decassílabo" era chamado "hendecassílabo" porque tem de fato ao todo 11 sílabas, e até 12 se terminar em palavra proparoxítona ou esdrúxula. O filologo brasileiro Manuel Said Ali no seu tratado voltou a contar todas as sílabas, segundo a tradição lusófona.

6 Ver CATULO, pp. 164 e 167. 
sem critério evidente. $\mathrm{O}$ mesmo Almeida Garrett, que traduziu os hendecassílabos falécios do poema 5 de Catulo por decassílabos, decassílabo para traduzir os escazontes de Catulo 31. Como dissemos, os tradutores traduzirem apenas uma recolha justifica a indiferenciação. No entanto, por traduzirmos todos epigramas, consideramos importante atribuir ritmo específico para verter o escazonte em português, particularmente um ritmo que contivesse o claudicar que existe no original.

Para tanto, propomos impor num metro elevado do português o tropeço do metro antigo, antecipando para a décima primeira sílaba a tônica final do dodecassílabo. O hendecassílabo resultante, segundo o andamento produzido, é pouco habitual em língua portuguesa e contribui para sensação de estranhamento. Veja-se o seguinte exemplo:

Erras, meorum fur auare librorum [...] (MART. I, 66, 1)

Er / ras, / la / drão / a / va / ro / dos / meus / li / vri / nhos

$1 / 2 / 3 / 4 / 5 / 6 / 7 / 8 / 9 / 10 / 11 / 12$

O ritmo interno do poema é o mesmo de um dodecassílabo, com acentuação interna na sexta sílaba poética, exceto pelo fim, em que antecipação da sílaba tônica causa efeito análogo de tropeço. Para aumentar o efeito claudicante, recorremos tantas vezes quanto foi possível ao uso de palavras derivadas, cuja cadência pode induzir o leitor a acentuá-las numa sílaba diferente da esperada, já que a palavra primitiva poderia soar mais natural. Este é o caso do exemplo acima (I, 66, 1), em que a leitura fluida do texto induzirá a ler "livro", e não "livrinho", aumentando o efeito claudicante.

Outro recurso que visa a realçar o efeito claudicante do escazonte é a contiguidade de duas tônicas, na décima e na décima primeira sílabas. Sendo um dos vícios rejeitados pela metrificação tradicional em nossa língua, o acento na sílaba anterior à tônica compromete a fluidez do ritmo, mais ou menos como ocorre no escazonte. Assim como o recurso às palavras derivadas, este foi inserido ocasionalmente nos poemas vertidos neste metro, sempre que não prejudicasse o sentido original.

A coletânea que apresentamos a seguir apresentará poemas representativos não apenas de cada metro, mas das várias matérias epigramáticas.

1. Livro 1, Epigrama 53 (matéria invectiva - irascimur); hexâmetro datílico.

Una est in nostris tua, Fidentine, libellis

pagina, sed certa domini signata figura, 
quae tua traducit manifesto carmina furto.

Sic interpositus uillo contaminat uncto

urbica Lingonicus Tyrianthina bardocucullus,

sic Arrentinae uiolant crystallina testae,

sic niger in ripis errat cum forte Caystri,

inter Ledaeos ridetur coruus olores,

sic ubi multisona feruet sacer Atthide lucus,

inproba Cecropias offendit pica querelas.

Indice non opus est nostris nec iudice libris, stat contra dicitque tibi tua pagina "Fur es".

Tradução: dodecassílabo com acento obrigatório na 6a. sílaba.

Uma página tua existe em meus livrinhos,

marcada, Fidentino, co'o rosto do dono

que acusa teus poemas de flagrante furto.

Assim, mesclado, ungido em pelos, contamina

as púrpuras urbanas o manto lingônico,

assim, copos de Arécio $^{7}$ os de cristal violam,

assim, negro, se acaso margeia o Caístro ${ }^{8}$,

o corvo sofre o riso dos cisnes de Leda',

assim, fervendo o bosque com Átis canora,

ímproba pega ofende os lamentos cecrópios.

Meus livros não precisam de indício ou juiz:

se interpõe tua página e diz: "És ladrão".

2. Livro 1, Epigrama 101 (matéria funerária - dolemus); dístico elegíaco.

Illa manus quondam studiorum fida meorum

et felix domino notaque Caesaribus,

destituit primos uiridis Demetrius annos:

7 Arrécio: Arrentina: cidade de fundação etrusca, atual Arezzo, na Toscana. Produzia cerâmica, segundo Plínio, o Velho XXXV, 160), a famosa cerâmica aretina.

8 Caístro: Caystri: rio da Ásia Menor que corria nas proximidades de Éfeso. A presença de aves ali é tema de Virgílio (Georg. I, 383-384).

9 Cisnes de Leda: Laedeos olores: assim chamados porque foi em cisne que Júpiter se transformou para conquistar Leda. 
quarta tribus lustris addita messis erat.

Ne tamen ad Stygias famulus descenderet umbras, ureret inplicitum cum scelerata lues,

cauimus et domini ius omne remisimus aegro: munere dignus erat conualuisse meo.

Sensit deficiens sua praemia meque patronum dixit ad infernas liber iturus aquas.

Tradução: dístico de dodecassílabo com acento obrigatório na 6a sílaba e decassílabo heroico.

Aquela mão, fiel outrora aos meus trabalhos, fértil ao dono, aos césares notória,

Demétrio abandonou nos verdes, jovens anos: somava a quarta messe aos seus três lustros ${ }^{10}$.

Mas para não descer escravo à sombra estígia ${ }^{11}$, pois lhe ardia cruel doença dentro,

cuidei que de senhor cessasse meu direito, para sua melhora um prêmio justo.

Notou, ao se extinguir, seu prêmio e me chamou "patrono", e às águas ínferas foi livre.

3. Livro 2, epigrama 5 (matéria queixosa - querimur); dístico elegíaco.

Ne ualeam, si non totis, Deciane, diebus et tecum totis noctibus esse uelim.

Sed duo sunt quae nos disiungunt milia passum:

quattuor haec fiunt, cum rediturus eam.

Saepe domi non es; cum sis quoque, saepe negaris:

uel tantum causis uel tibi saepe uacas.

Te tamen ut uideam, duo milia non piget ire;

ut te non uideam, quattuor ire piget.

10 Lustro: lustris: período de cinco anos. Demétrio, secretário de Marcial, teria, portanto, 19 anos.

11 Sombra Estígia: Stygias umbras: o Estige é rio que separava o mundo dos vivos do mundo dos mortos (“águas ínferas”). 
Tradução: dístico de dodecassílabo com acento obrigatório na 6a sílaba e decassílabo heroico.

Que eu morra se contigo não quero, Deciano passar o dia inteiro e toda a noite.

Dois mil passos, porém, te separam de mim: completam quatro quando eu retornar.

É comum não estares ou, se estás, negares, quer te ocupes de causas ou de ti.

Dois mil passos andar, mas te ver, não me enfada: me enfada andar os quatro e não te ver.

4. Livro 2, epigrama 21 (matéria jocosa - ludimus); dístico elegíaco.

Basia das aliis, aliis das, Postume, dextram.

Dicis 'Vtrum mauis? elige.' Malo manum.

Tradução: dístico de dodecassílabo com acento obrigatório na 6a sílaba e decassílabo heroico.

A alguns dás beijos, Póstumo, aos outros a destra.

"Qual preferes? Escolhe!" Escolho a mão.

5. Livro 2, epigrama 57 (matéria jocosa - ludimus); escazonte.

Hic quem uidetis gressibus uagis lentum, amethystinatus media qui secat Saepta, quem non lacernis Publius meus uincit, non ipse Cordus alpha paenulatorum, quem grex togatus sequitur et capillatus 5 recensque sella linteisque lorisque, oppignerauit modo modo ad Cladi mensam uix octo nummis anulum, unde cenaret.

Tradução: hendecassílabo com acentos obrigatórios na 6a e na 11a sílabas. Este que vês com vagos passos, molenga, que corta meio Septa ${ }^{12}$ em veste ametista

12 Septa: Saepta: edifício no Campo de Marte destinado ao comércio. 
que o meu Públio não vence pelas lacernas

nem mesmo Cordo, um alfa dos penulados ${ }^{13}$,

que o rebanho de toga e escravinhos seguem

e uma liteira nova e rédea e cortinas,

faz pouco penhorou na banca de Clado

o anel por oito numos, com quais jantasse.

6. Livro 3, epigrama 33 (matéria erótica - amamus); dístico elegíaco.

Ingenuam malo, sed si tamen illa negetur,

libertina mihi proxuma condicio est.

Extremo est ancilla loco: sed uincet utramque,

si facie nobis haec erit ingenua.

Tradução: dístico de dodecassílabo com acento obrigatório na 6a sílaba e decassílabo heroico.

Prefiro a livre. Se ela, contudo, se nega, a liberta é a seguinte condição.

A escrava em último lugar, mas vence as outras se para mim tiver um rosto livre.

7. Livro 3, epigrama 44 (matéria invectiva - irascimur); hendecassílabo falécio.

Occurrit tibi nemo quod libenter quod, quacumque uenis, fuga est et ingens

circa te, Ligurine, solitudo,

quid sit, scire cupis? Nimis poeta es.

Hoc ualde uitium periculosum est.

Non tigris catulis citata raptis,

non dipsas medio perusta sole,

nec sic scorpios inprobus timetur.

Nam tantos, rogo, quis ferat labores?

Et stanti legis et legis sedenti,

currenti legis et legis cacanti.

13 Penulados: paenulatorum: isto é, vestido com a pênula, espécie da capa de uso popular. 
In thermas fugio: sonas ad aurem.

Piscinam peto: non licet natare.

Ad cenam propero: tenes euntem.

Ad cenam uenio: fugas sedentem.

Lassus dormio: suscitas iacentem.

Vis, quantum facias mali, uidere?

Vir iustus, probus, innocens timeris.

Tradução: decassílabo heroico.

Por que ninguém te encontra de bom grado,

por que fuga onde quer que vás e imensa

solidão, Ligurino, te rodeia,

queres saber? Poeta és demasiado.

Isto é vício em excesso perigoso.

Nem tigre que excitou roubo das crias,

nem a cobra que acende ao sol a pino,

e o escorpião se deve assim temer.

Quem suporta, eu pergunto, tanto esforço?

Eu de pé, lês e lês se estou sentado,

se eu corro, lês e lês se estou cagando.

Fujo pras termas: cantas ao ouvido.

Busco a piscina: nem nadar se pode.

Corro ao jantar: deténs-me quando vou.

Chego ao jantar: me afastas quando sento.

Cansado, durmo: um morto ressuscitas.

Queres ver quanto fazes tu de mal?

És justo, probo, inócuo e és temido.

8. Livro 4, epigrama 71 (matéria erótica e jocosa-amamus); dístico elegíaco.

Quaero diu totam, Safroni Rufe, per urbem, si qua puella neget: nulla puella negat.

Tamquam fas non sit, tamquam sit turpe negare, tamquam non liceat, nulla puella negat.

Casta igitur nulla est? Sunt castae mille. Quid ergo

casta facit? Non dat, non tamen illa negat. 
Tradução: dístico de dodecassílabo com acento obrigatório na 6a sílaba e decassílabo heróico.

Busco há tempos, Safrônio Rufo, na urbe inteira, a moça que negou: nenhuma nega.

Como se fosse torpe negar, ou nefasto, ou fosse ilícito: nenhuma nega.

Não há castas? Milhares há. Mas como a casta

faz? Não dá, mas porém também não nega.

9. Livro 6, epigrama 82 (matéria jocosa-ludimus); hendecassílabo falécio.

Quidam me modo, Rufe, diligenter inspectum, uelut emptor aut lanista, cum uoltu digitoque subnotasset, "Tune es, tune" ait "ille Martialis, cuius nequitias iocosque nouit aurem qui modo non habet Batauam?"

Subrisi modice, leuique nutu me quem dixerat esse non negaui. "Cur ergo" inquit "habes malas lacernas?" Respondi: "quia sum malus poeta".

Hoc ne saepius accidat poetae, mittas, Rufe, mihi bonas lacernas.

Tradução: decassílabo heroico.

Há pouco um tipo, Rufo, olhou-me atento como de atletas mestre ou comprador, quando com rosto e dedos me apontou: "Não és", falou, "aquele Marcial cuja malícia e graça é conhecida por quem não tem o ouvido de um batavo?"

Moderado, sorri com leve aceno e não neguei que eu era quem falou. "Então por que tens capas tão ruins?" Respondi: "porque sou ruim poeta". 
Pra isto não ocorrer mais ao poeta,

Me manda, Rufo, algumas capas boas.

10. Livro 7, epigrama 24 (matéria invectiva - irascimur); dístico elegíaco.

Cum Iuuenale meo quae me committere temptas, quid non audebis, perfida lingua, loqui?

Te fingente nefas Pyladen odisset Orestes, Thesea Pirithoi destituisset amor,

tu Siculos fratres et maius nomen Atridas

et Ledae poteras dissociare genus.

Hoc tibi pro meritis et talibus inprecor ausis, ut facias illud quod, puto, lingua, facis.

Tradução: dístico de dodecassílabo com acento obrigatório na 6a sílaba e decassílabo heróico.

Se tentas confrontar-me com meu Juvenal,

pérfida língua, o que dizer não ousas?

Co' o que crias, Orestes odiaria Pílades ${ }^{14}$

falta o amor de Pirítoo a Teseu ${ }^{15}$,

os sículos irmãos ${ }^{16}$, o renome dos átridas

e as crianças de Leda ${ }^{17}$ apartarias.

Isto, pelo teu mérito e ousadia eu rogo:

que faças, língua, o que acho que já fazes.

11. Livro 9, epigrama 34 (matéria laudatória); dístico elegíaco.

Iuppiter Idaei risit mendacia busti,

dum uidet Augusti Flauia templa poli,

atque inter mensas largo iam nectare fusus,

14 Orestes... Pílades: Pyladen... Orestes: heróis cuja amizade era proverbial.

15 Pirítoo... Teseu: Thesea Pirithoi: heróis que participaram juntos de muitas aventuras, tais como a frustrada tentativa de sequestrar Perséfone no mundo inferior, que resultou no confinamento definitivo de Pirítoo nos infernos (APOLLOD. Bibl., II, 5, 12ss).

16 Sículos Irmãos: sículos fratres: refere-se provavelmente a Anfíon e seu rmão, que salvaram os pais da erupção do Etna (PS.-VIRG. Aet., 625-629).

17 Crianças de Leda: Ledae... genus: Castor e Pólux. 
pocula cum Marti traderet ipse suo,

respiciens Phoebum pariter Phoebique sororem,

cum quibus Alcides et pius Arcas erat:

"Gnosia uos", inquit, "nobis monumenta dedistis:

cernite quam plus sit Caesaris esse patrem".

Tradução: dístico de dodecassílabo com acento obrigatório na 6a sílaba e decassílabo heróico.

Jove ri desse embuste dos bustos ideus

vendo o templo dos Flávios ${ }^{18}$ de seu posto

e, no festim, por muito néctar já tomado,

deixando até seus copos ao seu Marte,

voltando os olhos tanto a Febo quanto à irmã,

com quem o Árcade ${ }^{19}$ pio e Alcides via,

diz: "Monumento em Cnossos destes vós a mim:

vede que vale mais ser pai de César".

12. Livro 10, epigrama 47 (matéria sapiencial); hendecassílabo falécio.

Vitam quae faciant beatiorem, iucundissime Martialis, haec sunt:

res non parta labore, sed relicta;

non ingratus ager, focus perennis;

lis numquam, toga rara, mens quieta;

uires ingenuae, salubre corpus;

prudens simplicitas, pares amici;

conuictus facilis, sine arte mensa;

nox non ebria, sed soluta curis;

non tristis torus et tamen pudicus;

somnus, qui faciat breues tenebras:

quod sis, esse uelis nihilque malis;

summum nec metuas diem nec optes.

18 Templo dos Flávios: Flavia templa: o templo que Domiciano mandou erigir no local em que nasceu (SUET. Dom., 1).

19 Árcade: Arcas: filho de Júpiter e Calisto, mítico ancestral do povo árcade. Depois de sua morte, foi colocado na constelação Arctofílax (HYG. Fab. 176; Astr. II, 4). 
Tradução: decassílabo heroico.

O que transforma a vida em mais feliz, amabilíssimo Marcial, é isso:

bens ganhos não no esforço, mas herdados, um fogo em nada ingrato, eterna chama, pleito algum, toga rara, mente em calma, força nativa, corpo com saúde, cauta simplícia, amigos semelhantes, convívio fácil, mesa sem requintes, noite não ébria, mas de angústias livre, cama não triste, mas, porém, pudica, um sono que abrevie a escuridão, não querer nada mais que ser quem és, não temer nem pedir o último dia.

13. Livro 11, epigrama 97 (matéria jocosa - ludimus); dístico elegíaco.

Una nocte quater possum: sed quattuor annis si possum, peream, te Telesilla semel.

Tradução: dístico de dodecassílabo com acento obrigatório na 6a sílaba e decassílabo heróico.

Dou quatro numa noite, mas se em anos quatro der uma, Telesila, em ti, que eu morra.

14. Livro 14, epigrama 120 (apoforeto); dístico elegíaco.

Ligula argentea

Quamuis me ligulam dicant equitesque patresque, dicor $\mathrm{ab}$ indoctis lingula grammaticis.

Tradução: dístico de dodecassílabo com acento obrigatório na Ga sílaba e decassílabo heróico.

Colher de prata

Mesmo que o équite diga, e o patrício, "cuié", burro, o gramático me diz "colher". 


\section{Referências}

ANTOLOGIA PALATINA. The Greek Anthology, with an English translation by W. R. Patton. 5 vols. London/New York: Heinemann/Putnam, 1920.

CASTILHO, Antônio Feliciano de. Tratado de Metrificação Portugueza. Seguido de Considerações sobre Declamação e a Póetica; pelo Visconde de Castilho. 4a ed. revista e augmentada. Porto: Livraria Moré-Editora, 1874.

CATULO. O Livro de Catulo, tradução, introdução e notas de João Angelo Oliva Neto. São Paulo: Edusp, 1996.

HOMERO. Ilíada, tradução de Carlos Alberto Nunes. Rio de Janeiro: Ediouro, 2001.

MARTIALIS. Epigrammata, recognovit brevique adnotatione critica instruxit W. M. Lindsay. Oxonii: e Typographeo Clarendoniano, 1987.

PAES, José Paulo. Poesia Erótica em Tradução. São Paulo: Companhia das Letras, 2006.

PIGNATARI, Décio. 31 Poetas, 214 poemas. São Paulo: Companhia das Letras, 1996.

PLINE, LE JEUNE. Lettres, texte ét. et trad. par Anne-Marie Guillemin. Vol. 2, Livres IVVI. Paris: Les Belles Lettres, 1955.

POSIDIPO DI PELLA. Epigrammi, a cura di Guido Bastianini e Claudio Gallazzi. Milano: LED Edizioni Universitarie, 2001.

RAMOS, Péricles Eugênio da Silva. Poesia Grega e Latina. São Paulo: Cultrix, 1964.

SAID ALI, Manuel. Versificação Portuguesa. Prefácio de Manuel Bandeira. São Paulo: Edusp, 1999. 